\title{
Analysis of Approaches of Communication in the Fight Against Hiv/Aids in Higher Education Institutions:

\author{
The Case of Bahir Dar University Anti-Hiv/Aids Movements (Ethiopia)
}

\author{
Adem Chanie Ali, Bahir Dar University, Ethopia \\ Lemma Kassaye Sileshi, Bahir Dar University, Ethiopia
}

\begin{abstract}
The study sheds light on the approaches of communication in higher education institutions in Ethiopia with special focus on Bahir Dar University. For this end, qualitative approach has been employed to gather the data required. The findings obtained reveal that the university anti-HIV/AIDS movements have become dependent on print media which were provided by NGOs and GOs for communicating their goals though the campaign against HIV/AIDS requires multidimensional tools. Unable to integrate other communication approaches such as broadcast media and internet has made the movements to fail to achieve the desired goals set as an end. The movements' lack of clear strategic plan has also contributed its own role for the movements not to be successful in their attempt to fight the pandemic. Moreover, lack of commitment on the part of the management of the university, infrequent trainings and other social events, lack of coordination and financial problems have highly hindered the movements' communication works. Thus, the findings have clearly revealed that communication has been downplayed in the movements' attempts to fight the epidemic. Because of this, behavior change in BDU is still unattainable goal. To alleviate the problem, it is highly recommended that a clear strategic plan needs to be designed in the way it directs clear, appropriate and integrated communication approaches, employing both mass media and non mass media outlets in addition to interpersonal communication for effective communication works.
\end{abstract}

Keywords: HIV /AIDS, communication approaches, communication practices, behavior change communication, communication strategy, integrated communication 


\section{Current Status of HIV/AIDS in Ethiopia}

Ethiopia as one of the countries of Africa, especially, as Sub-Saharan countries whose populations are vulnerable to the pandemic is experiencing a great problem due to HIV/AIDS. The epidemic has killed hundreds of thousands; it has left thousands of children orphans and it has still left the elderly without supporters. Though the decline in the prevalence of the epidemic is seen in the world in general, it seems to be less in the SubSaharan countries for different reasons. It may be attributed to poverty that led many people to be exposed to the epidemic; the other being lack of appropriate channels of communication to raise awareness among the different sections of the society and among different age groups. Moreover, NGOs working in these countries are working in accordance with their preset programs and projects which in turn do not allow them to be flexible to act according to the context in which they are working.

Viewed from its prevalence, the spread of the virus seems to be high among the young, the most active section of the society. As reports show the young people are among those people who are at most- risk. According to the report of Federal $\operatorname{HAPCO}(2010)$ the following populations are at higher risk of HIV infection: sex workers, uniformed services, longdistance-trucker-drivers; refugees and displaced people, daily laborers, mobile/migrant laborers, including cross-border population, street children, high school and university students, out-of-school youth and indigenous populations in remote foreign tourist destinations involved in transactional sex. The above mentioned groups of people are the most important productive sections of the society. If these sections of the society are at risk, it is easier to estimate that the whole population is endangered. With an estimated 1.2 million people living with HIV, Ethiopia has one of the largest populations of HIV infected people in the world (Federal HAPCO.

Goes with it, Nigatu and Semen (2011) have also added the following about the prevalence of the epidemic. Although HIV/AIDS is showing a decline, it remains one of the leading obstacles to health and development for poor countries; there are still a huge number of people infected and affected by HIV. Ethiopia being one of the African countries is not an exception to the prevalence. 
In response to this phenomenon, governmental and non-governmental organizations are seen working to minimize the prevalence significantly by designing different strategies. Among the strategies, they are using, varied communication strategies to bring about behavioral change among the people. However, their efforts of achieving their aims, goals and objectives do not seem to be successful for the reason that there is a gap in the body of communication works/ information provided to the target audience to fight the epidemic. Although the prevalence seems to decline, the ratio/ percentage of it is very high when calculated and the people who are at higher risk are also very significant in number. This implies that there should be interventionary tasks that dig out the role communication plays in the fight against HIV/AIDS.

\section{Statement of the Problem}

HIV/AIDS has been one of the greatest health problems of the people of the world for years regardless of sex, age, color, race, religion and geographical location. The major problems related with the disease are economic, social, political, cultural and psychological other than the health problem it causes. These problems coupled with poverty in the least developed countries like Ethiopia are causing a big chaos. Obviously, the prevalence of the virus is faster among the productive section of the society (between ages 14 and 49) (Frehiwot, 2006). If this productive section of the society in the least developed nations is infected with HIVAIDS, the situation becomes more aggravated than it was. A great majority of higher institutions community being part of this age group are highly exposed to the virus. This is because partly higher institutions are the places where the young meet in a great number. And partly, these institutions host sexually very active section of the society.

Bahir Dar University being one of the greatest and pioneer in the country, hosts over 45 thousand students in all programs (regular, evening, summer, and distance) and more than two thousand academic, administrative and supportive staffs. Hosting this large number of people with multidimensional interactions, the university is a fertile ground for the prevalence of the HIV/AIDS. The university's proximity to Bahir Dar town, the capital of the Amhara National Regional State, and tourist destination, also contributes a lot to the vulnerability of the community to the virus. 
Although, many efforts are going on, studies show that HIV/AIDS prevention results are disheartening. With an estimated 1.2 million people living with the virus, Ethiopia is one of the largest populations of HIV infected people in the world (Federal HAPCO, 2010). As the report by HAPCO shows the epidemic continues to spread, despite the many efforts to change the situation. Moreover, and maybe even more important is that HIV/AIDS is now among us, and a daily fact of living in our universities. Thus, prevention, awareness raising and attitude change towards issues such as promiscuity, unprotected sex and other genderrelated issues remain vitally important to halt the prevalence of HIV/AIDS although little attention is paid. Seen from a bird view perspective, HIV/AIDS communication interventions have not been very successful. Much attention has not been given to the appropriate health communication approaches to address the above issues and to tackle the pandemic (Rico Lie, 2008). The way we approach communication is decisive for our social change agenda (creating generations free of HIV/AIDS). Many organizations that strive for the prevention and control of HIV/AIDS implement different communication approaches/strategies. The way in which communication is approached is crucial to prevent the virus/disease and has a role for the success or the failure of goals/projects (Alfonso, 2009). Thus, the study has tried to examine the approaches of communication and suggest the strategies which are presumed to be more appropriate to tackle this multidimensional problem.

\section{Objectives}

\section{General Objective:}

The principal objective of this study is to scrutinize the communication approaches that are used by BDU HIV/AIDS Movements

\section{Specific objectives}

\section{The study is intended to:}

- identify the communication mechanisms/approaches that are used by the Anti HIV/AIDS movements

- analyze communication strategies that are used by the Anti HIV/AIDS movements

- investigate barriers of communication (internal and external factors) which hinder the movements work

- identify conceptions of communication in the fight against HIV/AIDS 
- $\quad$ suggest appropriate methods of communication that would be effective to alleviate the deep rooted HIV/AIDS problems

\section{Research Questions}

To address the above-mentioned objectives, the following major questions were formulated

1. How are the movements working from health communication perspectives?

2. How communication is perceived in the university's HIV/AIDS fighting effort?

3. What are the dominant approaches of communication in BDU Anti HIV/AIDS Movements?

4. What channels are central for their external and internal communication work?

5. What messages are they trying to convey to the target groups?

6. What barriers affect the communication works of the universities anti HIV/AIDS movements?

\section{Research Methodology}

In order to assess the communication approaches employed to fight HIV/AIDS in Bahir Dar University, qualitative research method was applied. Different methods of data collection were applied with the view of obtaining sufficient information. The methods of data collection used were semi- structured interview with key informants, gathered documents and observation. In addition, personal experiences and informal conversations held with both the staff and students were also applied to enrich the data. Populations of the study are the community members of Bahir Dar Univesity of both campuses. Purposive sampling has been used for collecting the qualitative data. Samples had to be selected purposively because this sampling method enables to address specific questions for the concerned coordinators, experts and other stakeholders (Reinard, 1994) in order to elicit the required data to be dug out. This being the case, the researchers have selected people who have responsibilities and are working on HIV/AIDS. These include people from the HIV/AIDS coordinating office of the university, people from students anti-HIV/AIDS movement, people from staff antiHIV/AIDS movement (one of the researchers is the chairperson of the staff anti-HIV/AIDS movement and this has also made things easier for obtaining data from different sources). Moreover, people form academic, administrative and supportive staffs as well as some students who the researchers thought are resource persons were included to obtain reliable 
data. These subjects were included to corroborate the data obtained from coordinators, experts and others.

\section{Data Analysis}

Thematic analysis was used to address the different research questions and objectives set, for the reason that it helps analyze the data accordingly. The responses gathered from the subjects were analyzed after they were categorized and labeled, and in most cases, the responses fell under the categories that were spelled out in the thematic questions. Responses, which were found to be vital, relevant and consistent were presented and analyzed qualitatively.

\section{Results and Analysis}

\section{Main Objectives of Bahir Dar University (BDU) Anti- HIV /AIDS Movements}

The main objectives of BDU Anti- HIV/ AIDS Movements are prevention, controlling and coordination of anti-HIV/AIDS practices. The main focus is behavior change among the university community. According to the Anti HIV/AIDS Movement coordinators, the major problems in the university in relation to HIV/AIDS are the following:

- Multiple partnership is still the common practice among university students

- Unsafe sexual practices are observed during evening in the dark areas of the campuses

- Smoking, drinking and chewing that are becoming part of the culture of the university students.

- Lack of interest on the part of students to attend HIV/AIDS related trainings and workshops without being paid per diem which has become the headache for the movements.

- Less awareness and knowledge of students on reproductive health

- Less interest on the part of students to take VCT

- Students' spending their leisure time in bars and hotels specially during evenings

These undesired behaviors lead the students to unsafe sexual practices which are the main road to HIV/AIDS. These problems reflect the status of behavior change in the university visa-vis the efforts made by the anti HIV/AIDS movements and other stakeholders. 


\section{The Deferent Activities/ Strategies Employed by the Movements to Fight the Epidemic}

The following are the major activities done by the movements. These include:

- Providing information about HIV/AIDS

- Coordinating training on HIV/AIDS

- Making available leisure time entertainment such as chess and table tennis

- Organizing evening entertainments, coffee ceremony and drama

- Distributing condoms, yearly the movements provide around 75,000 condoms

- Creating opportunities of peer discussions on HIV/AIDS and other health related issues among students

Although the Anti HIV/AIDS movements of the university are striving to fight the epidemic by setting behavior change as a goal, the intended behavior change is not observed in the university. The limited efforts of the movements cannot reach all the fifteen thousand regular students and more than two thousand academic and non academic staff of the university as it has been discussed in the topics ahead.

\section{Communication Channels of the Anti- HIV/AIDS Movements}

The common communication channels used by the movements to address its goals and objectives are discussed subsequently.

\section{Print Media}

\section{* Booklet by Health Communication Partnership (HCP)}

The known booklet used by BDU students is called 'campus life' which is produced and distributed by health communication partnership (HCP). The main concern of the booklet is promoting self assessment to know the self status of the students pertaining to their sexual behaviors. It digs out factors that could expose students to HIV/AIDS and the counteractions or mechanisms that help students protect themselves from it. The factors that are discussed on the booklet are economic problems, peer pressure, chewing chat, taking alcohol, multiple sexual partners, failure to use condom and sexual harassment. It also narrates how campus life might lead to HIV/AIDS. The booklet assesses how risky behaviors such as taking alcohol and chewing chat might lead to HIV/AIDS in the university. Besides, the booklet deals with reproductive health problems such as unwanted pregnancy and mechanisms or tools used to tackle pregnancy and STI: abstinence, being faithful, using contraceptive 
methods (using condom, pills, diaphragm, etc), and sexual transmitted infection (STI) including syphilis, gonorrhea, chlamydia, and HIV with their symptoms and ways of treatment.

Generally, campus life booklet tries to equip the students with life skills. This trend of using booklet as a tool to enable students to protect themselves from HIVAIDS by raise awareness about it has a paramount importance. However, the problem lies in the way the booklet is distrusted and the way students are instructed to work with it, for it lacks clarity. Since the booklet is distributed among students who have already taken trainings by HCP, the great majority of the students do not have access to it. If distributed among many students and assisted with trainings, there would be the probability to achieve a significant change, for the effect is observable by the small number of students who have taken the booklet along with trainings. This limited distribution of the booklet contributes to communication gap in the works of the anti-HIV/AIDS movements of Bahir Dar University.

\section{* ded's booklets (German Aid Organization)}

During the data collection phase, the researchers were provided with ded booklets and the students were also seen reading the booklets at the AIDS resource centers of the university. The ded booklets focused on HIV/AIDS and reproductive health related issues. One of the booklets, named 'virginity', preaches students to be virgin in the hope that it would help female students protect themselves from contracting the infection and stakeholders fight HIV/AIDS and other reproductive health related problems. The remaining ded booklets try to create awareness about family planning, sexual behaviors, VCT and measures that should be taken after pregnancy. Factors that expose people to HIV/AIDS such as cultural, biological, economic, and psychological are also dealt in the booklets. For instance, having multiple sexual partner, early marriage, genital mutilation, etc, are among others mentioned as cultural practices. Biologically, females are more susceptible to HIV/AIDS, for their biological make up makes the situation more aggravated than it is. Lack of self reliance, unable to know more about one's sexual partner and being in hurry for first sexual intercourse and peer pressure are some of the psychological factors dealt. Economic factors lead the students to commit sexual intercourse with people who they do not know before for economic reasons. Moreover, the booklets address issues of HIV/AIDS and STI (Sexual Transmission 
Infection). The issues discussed in the booklets are supported by pictures of reproductive organs in the attempt to make the issues addressed as clear as possible.

However, surprisingly, the university as one of the big institutions in the country doesn't have its own pamphlets, booklets, magazines and newspapers in the fight against the epidemic. By producing its own print media, it could present real life experiences to the university community. All pamphlets and booklets are donated by NGOS. It made the attempts less effective since the booklets are produced in line with the programs, projects and objectives of the GOs and NGOS themselves. This in turn, creates gaps in the communication works of the movements of the university, for the NGOS and the university do not have a common plan in the fight. Thus, the movements are forced to distribute the above mentioned booklets and pamphlets among the university community rather than producing and distributing their own for the reasons mentioned earlier.

The print media distributed by NGOS are also not context specific. They generally address the issues of HIV/AIDS and reproductive health. For this reason, the communication work has failed to address the current situation of HIV/AIDS in the university. This is because the movements' communication has failed to provide tangible evidences, reports, and research findings about the risky behaviors that are observed in the university. And this couldn't enable the university and the surrounding community to get appropriate pieces of information about the situation. The information the community is gaining is rumor based, not supported by tangible evidences and researches. This has led the surrounding people to have two types of views about the university regarding to HIV/AIDS.

As experiences show that some people perceive as if the university is free from HIV/AIDS and are involved in unsafe sexual practices with some of the community members, for there is a gap in the body of the information of HIV/AIDS in the institution. And this shows that the community does not get actual information about risky behaviors that are observed among the university community.

On the other hand, this communication gap has made some people develop negative stereotypes about the university community in general and the students in particular. It created perceptions that spoil the image of the university in the sense that students are highly 
venerable to the pandemic. The worst of it is some people perceive that all most all female students are involved in prostitution due to rumors spread in the town. Such kind of views is also promoted by some of the NGOs. For example, Wise Up, one of the NGOs working in the university, once held a workshop for the university community 2010. In the workshop, there were different stakeholders. The main agenda of the workshop was "Are the university students or Bahir Dar town prostitutes more vulnerable to HIV/AIDS? ". As both of the researchers witnessed that, those who came from the NGOs strongly argued that the university female students are more vulnerable than the prostitutes. It can be imagined how such kinds of views and agenda spoil the image of the university and its respected community.

The saddest news is that the university does not give much attention for such kinds of image polluter issues. Even the university magazine named 'Papyrus' has not presented any information about HIV/AIDS so far. This shows that the big issue, HIV/AIDS has been given little attention.

\section{Broadcast Media}

It is clear that broadcast media have the potential in the fight against HIV/AIDS, especially to increase awareness and to get large audiences at a time. However, Bahir Dar University antiHIV/AIDS movements are not seen using broadcast media in the campaign. The university couldn't use even the nearest Amhara Mass Media Agency which is located in the town. Even they could make use of the mass media to enable the society to get clear information there by building the image of the university. In collaboration with Amhara Mass Media, they could do a lot about awareness raising, behavior change, community mobilization and advocacy. Although, there is no well planned relationship and collaboration with the mass media, there are inadequate programs aired by the mass media. This is even done by the initiatives of the mass media itself usually following workshops and festivals.

Mini-media plays a great role in raising awareness about health issues although its coverage and audience is limited. Hence, BDU could address its community with HIV/AIDS related issues and reproductive health using mini-media. The absence of mini-media in the university has made the communication practices more challenging. 


\section{Using Audio-Video Devices: The Puzzling Paradox!}

A lot could be done using audio-video devices to transfer messages that can help bring behavior change among the university community in general and among the students in particular. But this is not the case in BDU. This is one of the strategies that are overlooked by either the movements or by the university. Instead of using the devices for promoting behavior change, students are seen watching movies that motivate them to practice sex. The worst case scenario is that the graduating commute (GC) has invited students to blue films for its commercial purpose as the interviews held with the respondents and personal observations reveal. And this is observed to be the paradox for the movements' campaign against HIV/AIDS.

\section{New-Media-Internet: The Missed Opportunity!}

These days internet has changed the communication practices of organizations and individuals. The rise of new media has led to the advance of several social networking sites. By opening web site, the university HIV/AIDS movements could provide the community with different up to date information about HIV/AIDS. By using a web site, the movement could prepare a moderated forum for free discussions about sexual behaviors and practices and questions and answer sessions about HIV/AIDS issues. The movements could also release downloadable video clips, dramas and other different edutainments that target behavior and social change by using its web sites.

Besides, face book and twitter, social networks, could play a significant role in the movements work, especially; face book which has become a popular social networking site among the university community could be taken as a good opportunity to disseminate relevant pieces of information. This is the missed opportunity that the movement could use to teach the dangers of having multiple sexual partners, the benefit of VCT and the dangers of contracting the deadly virus. And it could be contributing for achieving the goals and objectives of the movements.

\section{Group Communications}

The students' anti-HIV/AIDS movement uses a group based communication strategy in the campaign. This group based communication has three levels of interactions: structurally, organized as the executive committee >ambassadors$>$ members. Accordingly, 
each ambassador coordinates five members in which the networking is functioning across students' residence/dormitories. The network is used to disseminate pamphlets, brochures, booklets and condoms. Members under each ambassador discuss heath related issues besides HIV/AIDS. By doing this, the movement reaches its 2500 members. This number is however, insignificant when viewed from the total number of the students (over fifteen thousand in the regular program only) the university is hosting. Their failure to reach the great majority of the students reveals that there exists communication gap in the movement's works. Moreover, alongside of ambassadors, there are also big brothers and sisters who share their experiences to their juniors. The more experienced and trained senior students share their knowledge, life skills, and experiences to their junior students who are living around their dormitories. Even though, this is found to be vitally important to address HIV/AIDS and other health related issues, its infrequent practice has restricted its effectiveness.

\section{Social Events}

Social events are helpful to raise awareness about social, cultural, health and other related issues. Nevertheless, the movements occasionally use coffee ceremony, evening entrainments such as drama, music, theatre, etc. The purpose of these social events in Bahir Dar University is aimed at addressing health related problems. Besides, entertaining students in the way they want can help hold their attention to convey a message about HIV/AIDS. Since most students are interested in evening entertainments, especially in music, drama, and theatre presented by the movements in collaboration with the cultural center of the university, the movements use this opportunity to address HIV/AIDS and reproductive health issues. This edutainment approach is recommended and used by many organizations around the world. Communication experts advocate that using education- entertainment approach is a good tool for social and behavior change in the society (Serves, 2008). As one of the social evils, HIV/AIDS is not an exception not to use edutainment approach. As far as personal experiences and observations are concerned, the movements could attract and reach relatively a larger number of students even though the effectiveness of this approach is not significantly observed in the university. This may be attributed to: 1 . infrequent organization of the social events, 2.redundancy of the programs in the social events, 3. unwise use of the edutainment approach, 4.timing of the social events 
Generally, the anti HIV/AIDS movement doesn't have a clear communication strategy although strategic communication offers a powerful set of tools for designing, implementing, and evaluating programs (McKee et al 2004). These authors also add that strategic communication provides guidance for both communication related to HIV/AIDS prevention, as well as treatment, testing, care and support. Without clear strategy communication, fighting with HIV/AIDS becomes like walking in a large desert without a compass. This shows that communication is downplayed in the fight against the pandemic in Bahir Dar University.

\section{Networking (partnership)}

The university HIV/AIDS Movements does have partners which are working on similar issues i.e. in the campaign against HIV/AIDS. The movements use telephone calls, letters, workshops, and interpersonal dialogues for communicating the different partners. Federal Higher Institutions Forum, Federal HAPCO, ARHAPCO, Bahir Dar town HAPCO, Bahir Dar town Higher Institutions Forum and Amhara Higher Education Forum are among governmental organization the HIV/AIDS coordinating office of the university (under which the different anti HIV/AIDS movements are working) is working with.

On the other hand, FGAE, HCP, DKT, Wise Up, OSSA, UNFPA, and ded, are the non government organizations which are actively involved in the campaign against HIV/AIDS. These organizations often work on HIV/AIDS in higher institutions. Since these NGOs are located in Bahir Dar town, they are attempting to work with Bahir Dar University HIV/AIDS movements. They support the movements by financing them, providing condom, trainings, and facilities such as computers and brochures. Some of these organizations have built centers for AIDS resources. However, the deferent GOs and NGOs are working in accordance with their programs and projects. And this creates a mismatch between the plans of the movements in the university and that of the GOS and NGOs mentioned earlier. Even though, some of the GOs call for a common plan with university at the beginning of each budget year, it doesn't help the movements to be effective in their campaign for the reason mentioned above. On the other hand, the movements' communication with the wider surrounding community is loose although tackling the spread of virus needs working with the 
surrounding community. There is no significant communication work done by the movements that targeted the surrounding community.

\section{Condom Promotion and Cultural Values}

The movements' distribute about 75,000 condoms among students annually. When this number is viewed from that of students' number, it is not adequate. The movements are seen to use different mechanisms to distribute the condoms among which promotion is one. Although some of the condom promotion aspects (using male sexual organ sample) seemed to cause cultural shock, the movements couldn't do or get any other options in order to show and promote condom use among students. Even for this secular oriented generation, it has caused cultural shock since it made them shy and retain to take active part in the promotion process of appropriate condom use. Of course, the movements have tried to make condoms available in different places of the university including such places as AIDS resource centers, cafeteria, on the gate of campus and near trees to enable condom users to feel unashamed while buying them for use. However, this kind of practice is not without a problem, for it exposes the condoms to be easily damaged because of poor handling of them since they are placed in unsafe places mentioned earlier.

\section{Communication Barriers and Challenges}

One of the problems the movements are facing is the movements do not have clear communication strategies. Lack of clear communication strategy in turn leaves the movements to fail in their efforts to achieve their goals and objectives. Still, the other problem which has played a central role is financial problem. The university doesn't budget for HIV/AIDS. It is because of lack of commitment on the part of the top level management of the university.

\section{HIV/AIDS Mainstreaming}

Although it has been given priority by the federal government to allocate a $2 \%$ annual budget for HIV/AIDS prevention and controlling, it has failed to be effected by Bahir Dar University, for the reason that top level managers have given it a deaf ear. The only thing the movements get from top level managers is a promise which evaporates within a day or two. This less commitment has highly affected the communication works of the movements as 
interviews held with the interviewees reveal. Shortage in finance has also forced the movements to conduct fragmented trainings.

Compounded with the above factors for failure to achieve the goals and objectives of the movements, the change in position of responsible top level managers of the university has highly held back the practice of making or achieving HIV/AIDS mainstreaming from being effected in the institution. The top level managers who are directly responsible to the issue continue to work for shorter span of time. Thus, it becomes extremely difficult for them to implement what they pledged to accomplish. And their shorter span in their positions of responsibility is seen to make them less committed to help HIV/AIDS mainstreaming.

The financial problem has left the movements to be under the influence of other GOs and NGOS which come up with their own plans and goals. The NGOs come up with unclear communication strategies which in turn confuse the community as what has been bone by these organizations. However, if the movements were well equipped with financial support by the university itself, they could achieve the designed goals set to fight the pandemic in the institution better than what has been done so far.

Lack of coordination between GOs and NGOs, and the movement is another challenge. Some of the NGOs and GOs involve in the campaign without informing/ without the knowledge of the movement. They work with insignificant number of students just for the sake of taking pictures for their own hidden agenda. Working without the consultation of the movements in the university is found to be ineffective as interviews conducted with some of the interviewees reveals. These inappropriate communication approaches of the NGOs have led the campaign to be less effective than could be better if practiced in the desired way.

All these barriers and challenges couldn't allow the movements to mobilize the community for fighting the prevalence of the epidemic. Surprisingly, most academic staff members do not know even the very existence of the movements as the informal discussions held with some of respondents reveal. This shows that the movements couldn't mobilize the university community. Without community mobilization ( $\mathrm{CN})$, the campaign against HIV/AIDS is thought to be a dream. McKee et al (2004) state that countries that are successful in igniting a social movement for HIV/AIDS prevention and care have a much greater chance of success 
in defeating the virus. However, the University anti HIV/AIDS movements failed to mobilize the university community.

Moreover, failure to design a curriculum for HIV/AIDS and less commitment to mainstream HIV/AIDS is the other problem observed in the university as the information gathered through interviews, personal experiences and observation reveal.

\section{Conclusion and Recommendations}

\section{Conclusion}

The research was conducted with the principal objective to scrutinize the approaches of communication in the fight against HIV/ AIDS in higher education institutions in Ethiopia with special focus on Bahir Dar University. Based on the objective set, the data was collected through interviews, observation and documents. Personal experiences and informal conversations were also used to substantiate the data. The data collected was analyzed qualitatively and the research has come up with the following major findings.

The main communication channels used by the movements to address its goals and objectives are print media such as booklets, pamphlets and brochures. These communication channels are provided by other GOs and NGOs. These communication tools preach to raise awareness about HIV/AIDS and reproductive health with ultimate goal of behavior change.

Since the university doesn't have its own print media, it is forced to be dependent on those which provide it. By producing its own print media, it could present real life experiences to the university community. Thus, lack of producing its own print media made the attempts less effective, for reason that the print media are produced in line with the programs, projects and objectives of the GOs and NGOS themselves. This in turn, creates gaps in the communication works of the movements of the university, for the NGOS and the university do not have a common plan in the fight.

Although broadcast media play a major role in the campaign against HIV/AIDS, the anti HIV/AIDS movements of the university have not made use of them. Besides, audio-video devices and the new media-internet are found to be the missed opportunity in the campaign. 
This reflects that the movements have failed to integrate the different communication approaches. This in turn has left its impact for the less effectiveness of the movements work.

There has been an attempt of using group communication in the fight against HIV/AIDS. Though group communication has its own importance to integrate the interpersonal communication with the mass media, its scope of implementation is very limited to some members of the movements. Social events such as coffee ceremony, music and drama are also used in the fight against HIV/AIDS with a very limited scope.

Generally, the communication works of the movements mirror that communication has not been given attention. The movements do not have clear communication strategy. The fragmented communication works of the movements show that there exists lack of understanding the role communication plays in the battle against HIV/AIDS. Thus, the overall activities of the movements are not effective as they planned. Because of this, behavior change in BDU is still a night mare.

\section{Recommendations}

Lack of clear communication strategy has hampered the movements work. The movements have been working without clear strategic plan that could not enable them to use appropriate and integrated communication approaches and this resulted in failure to achieve the intended behavior change. To alleviate this problem, a clear strategic plan ought to be developed in the way it directs clear, appropriate and integrated communication approaches, using different mass media and non mass media outlets in addition to interpersonal communication for effective communication works.

Lack of commitment on the part of the top level managers of the university has contributed a lot for the unsuccessful practices of HIV/AIDS movements. Because of this problem, HIV/AIDS mainstreaming has not been put into practice in the university even if the government of Ethiopia has developed a policy of allocating a $2 \%$ budget for HIV/AIDS mainstreaming. And the other related problem to this less commitment is that it has hindered from integrating HIV/AIDS in the curricula. Hence, it is strongly recommended that the commitment of the top level managers of the university has a paramount importance to make the HIV/AIDS works effective enough. 
Lack of coordination among the movements, GOs and NGOs has added problem to the challenges of the movements. Since GOs and NGOs do not have common approaches to address HIV/AIDS and other reproductive health issues, there exists a gap in the works of the movements and thus, the practices of these stakeholders have not brought about the intended out comes or the desired behavioral change. To be effective in these pressing societal problems, it is recommended that there should be a common plan, strategy and approaches among stakeholders 


\section{References}

Alfonso, G. 2008. Communication for social change. Retrieved from knol.google.com/.../alfonso/communication-for-socialchange/.../2 May.20, 2009.

Family Health International (FHI). 2005. Strategic Behavioral Communication (SBC) for HIV/AIDS: A frame work

Federal HIV/AIDS Prevention and Control Office (2010) Report on progress towards Implementation of the UN Declaration of Commitment on HIV/AIDS: Addis Ababa, Ethiopia

Frehiwot Alebachew. 2006. Behavior Change Communication and the Response of Young Adults: the Case of Ethiopia. Save lives Ethiopia(Sale). Relief and Development Organization.

HAPCO and Global HIV/AIDS Monitoring and Evaluation Team (GAMET) (2008). HIV / Aids

in Ethiopia -An epidemiological synthesis. The Global HIV/AIDS Program, the World

Bank, Washington, DC

HAPCO. 2010. Report on Progress towards Implementation of the UN Declaration of Commitment on HIV/AIDS. Addis Ababa

HAPCPO. 2011. HIV Behavior Change Communication Framework (Ethiopia). Addis Ababa

Madise, K. 2010. A Communication Brief for an HIV/AIDS and Reproductive Health intereducative Program for the Youth in Malawi. http://marshalmadise.blogspot.com/2010/11.

Mcphail T(ed). 2009. Development Communication: Reframing the Role of the Media. Wiley- Balckwell:

MeKee etal 2004. Strategic Communication in the HIV/AIDS Epidemic. Sage Publications: London

Nigatu R and Seman K 2011. Attitudes and Practices on HIV Preventions among Students of Higher Education Institutions in Ethiopia: International Research Journals, The case of Addis Ababa University.

Reinard, John.1994. Introduction to Communication Research. Madison: Brown and Benchmark. 
Rico Lie, 2008. Rural HIV/AIDS Communication /Intervention: From Using Models to Using Frame Works and Common Principles. In Communication for Development and Social Change. SAGE. Los Angeles. www. Sag publications.com

Serveas, J(Ed.). 2008. Communication for Development and Social Change. SAGE. Los Angeles. www. Sag publications.com

Taylor, S \& Bogdan, R. 1998. Introduction to Qualitative Research Methods: A Guide and Resource .3rd ed. John \& Sons. Inc.USA

Thomas R. 2006. Health communication. Springer Science and Business Media, inc: New York

www.worldbank/aid 